\title{
Measuring prices in the electronic communications market: some thoughts about non-linear tariffs for mobile phone calls
}

\author{
Begoña García Mariñoso \\ Íñigo Herguera \\ David Suárez* \\ Department of Studies and Statistics \\ Comisión del Mercado de las Telecomunicaciones (CMT) \\ Barcelona
}

\begin{abstract}
In this paper we show how two apparently similar ways to report mobile call prices: the average expenditure per minute and the average revenue per minute can differ in a striking way. The non-linearities of mobile tariffs, especially the widespread use of two part tariffs which consist of a minimum expenditure and call connection fees, underlie the difference between the two types of price proxies. Whilst average revenue per minute informs about operators yields, average expenditure per minute is an indicator of the effectiveness of price discrimination.
\end{abstract}

Keywords: mobile, nonlinear pricing.

JEL classification: D12, L51, L96.

\section{Resumen}

En este artículo mostramos cómo dos maneras aparentemente similares de reportar el precio de las llamadas de móvil, el gasto medio por minuto y el ingreso medio por minuto, pueden diferir de forma sorprendente. Las no linealidades de las tarifas de móvil, en especial el uso habitual de tarifas de dos partes que conllevan un gasto mínimo y los gastos por establecimiento de llamada, subyacen tras las diferencias entre las dos aproximaciones al precio por minuto. Mientras que el ingreso por minuto revela información sobre los rendimientos de los operadores, el gasto por minuto es un indicador de la efectividad de la discriminación de precios.

Palabras clave: móviles, precios no lineales.

Clasificación JEL: D12, L51, L96.

\section{Introduction}

For many good reasons, accurate price level information is in every regulator's wish list, along with service penetrations and market shares. Despite acknowledging a few exceptions, it is generally accepted that in markets with more competition, margins tend to be smaller. In consequence, data on prices is used in a very blunt

* The views expressed are entirely those of the authors and do not necessarily represent those of CMT. The usual caveat applies. 
way to convey information on the degree of competition in different markets, typically by either comparing price levels of different geographical areas or by tracking price changes with time. The electronic communications market is not an exception to this. The European Commission (EC) regularly publishes a report on telecom prices, which compares prices of services across European Union (EU) members ${ }^{1}$. Or alternatively, in the introductory chapter of its latest implementation report $^{2}, 7$ out of 12 figures directly report price levels or differences between price levels between the EU members. CMT, the Spanish Telecom Regulator, also publishes price data for all national markets in its annual report ${ }^{3}$ and also every semester for European broadband prices ${ }^{4}$.

Despite this, nowadays, producing relevant information on price levels is a very challenging task which combines the need to communicate a clear message with rigorous measurement. In the case of telecom services, the main problem (especially in downstream markets) is the availability of all sorts of non linear tariffs, in combination with the lack of detailed information on the number of consumers that are subscribed to each tariff. In most cases, all that National Regulatory Agencies (NRAs) have are lists of nominal tariffs and information on aggregate revenues and consumption levels, which are both easily available from operators. Therefore, the different institutions have resorted to either proxy price levels directly by using average revenues per user, line or minute or to use theoretical consumer profiles, known as baskets, which coupled with each single tariff allow for the computation of a hypothetical expenditure of a consumer per tariff. As a result, in this last case, the different institutions must decide how to summarize all this information on tariffs in one or two indicators, and usually choose to report the minimum or average expenditure per basket.

The criticisms on the basket methodology are well known ${ }^{5}$. First, given the differences in national consumer tastes and in market characteristics, not all consumer profiles are equally relevant in all countries. Because of this, the basket methodology can result in very unfortunate results when an unreasonable profile is used to characterize some national market or to compare it with another. On top of this, as mentioned above, the information on how popular different tariffs are is limited or unknown and, in consequence, it is not possible to guarantee that the

\footnotetext{
1 See the EC Report on Telecoms Price Developments from 1998 to 2008 at: http://ec. europa.eu/information_society/policy/ecomm/doc/library/ext_studies/price_developments_1998_2008 Itariff_trends_report_1998_2008.pdf

2 See chapter 1 of the 15 th Progress Report on the Single European Electronic Communications Market - 2009, available at: http://ec.europa.eu/information_society/policy/ecomm/library/ communications_reports/annualreports/15th/index_en.htm

${ }^{3}$ See CMT Informe Anual 2009 at: http://www.cmt.es/cmt_ptl_ext/SelectOption.do?nav=publi_ anuales \&detalles $=09002719800 a 2475$ \& pagina $=1$

${ }^{4}$ See Comparativa de precios de banda ancha (Junio 2010) at: http://www.cmt.es/es/publicaciones/ anexos/101229_InformeBA_Junio2010.pdf

${ }^{5}$ See for example the ERG (08) public report "Methodology on the proposal for comparison of Broadband Retail Prices".
} 
offers informed are the most relevant ones in the marketplace. This is, for example, the averages reported normally are simple means that have not been weighted by the number of customers.

In addition to the usual set of information, CMT also has data on individual household consumption and expenditures collected directly from the bills of a representative sample of Spanish households. These data are in many ways a strong complement to the data provided by operators. In particular, in this paper we will examine how this data may be used to proxy price levels and, in this way, enrich the standard analysis of the average revenue per user/per minute analysis. Note that the household data allows to compute average expenditure levels by minute ${ }^{6}$ in several ways: either by averaging expenditures per minute across households or simply by summing up all expenditures and minutes and computing an aggregate average, which is similar to average revenue. Secondly, the household data also enables to proxy prices for consumer groups by their consumption levels and have a better picture of the expenditures per unit of consumption of different consumer typessomething that is quite important where price discrimination is possible.

\section{Information sources at CMT}

In order to better perform its functions CMT is empowered by Ley 32/2003, General de Telecomunicaciones, 2003 to request data from operators, both in an adhoc basis to inform a Council decision, but also regularly for statistical purposes (monthly, quarterly and annually). The latter information is varied and rich. It includes data on revenues, consumption, clients, infrastructures, portability and many others. Most of this data is collected at a subnational level and part of it is geographically indexed. The data provided by the operators is thoroughly revised by CMT - unreasonable trends are detected and data is checked for internal and external inconsistencies.

In addition, CMT also purchases data from several providers. For example CMT and Red.es ${ }^{7}$ regularly outsource the field work necessary to gather data from households and individuals. During 2010 this task was performed by Taylor Nelson Sofres (TNS). These data known as "Panel de Hogares" consists of two types of information. First, there is survey information that is collected twice a year from a sample of Spanish households (a questionnaire per household and a questionnaire for each household member). Second, there is data which is processed directly every quarter from all the electronic communication bills of a set of households. In 2010 the sample sizes were of around 3,000 households and over 6,000 individuals for the questionnaires and around 2,500 households for the bill harvesting data. The

\footnotetext{
6 Or by call.

7 Red.es is a public business entity dependant of the Ministry of Industry, Tourism and Trade that is in charge of driving the development of the Information Society in Spain.
} 
samples were selected with aproportional quotas for Comunidad Autónoma ${ }^{8}$ (so that small Comunidades Autónomas have sufficiently large numbers), and then, proportional quotas for the population of municipalities, household socioeconomic status and household size.

In this paper we use the household data and the operator data for the second quarter of 2010 to illustrate some of the problems in reporting price indicators and explain how different methodologies result in price indicators that fit different information objectives.

\section{Non linearities in mobile call tariffs}

A characteristic of call services is the great diversity of available tariffs. These can depend on the time of the call (peak and off peak), the destination network (onnet and off-net) or number ("friends and family numbers" or "preferred numbers"), and include all types of non linearities, such as volume discounts or semi-flat rates. Given this tariff complexity it is not easy to summarise all this information in a few indicators, something that is desirable in public reporting. Traditionally European NRAs and the EC have proxied prices using average revenue per minute or per call, normally sourced directly from operators (i.e. total revenue/total number of minutes). This is a good indicator: it is simple to understand and calculate and it allows for clear cut comparisons between regions or periods. However, average revenue per minute may not be such a good description of the price paid by households for their call services. A different indicator can be obtained by calculating the mean of the expenditure per minute of the different households in the bill harvesting sample, which we will denominate the average expenditure per minute. As we will see this indicator does not coincide, and for good reasons, with the average revenue per minute sourced by operators. In this way, the household and operator databases prove to be complementary in nature and a mean by which a regulatory agency can get at a more complete picture of market behaviour.

\subsection{Sources of differences between the average revenue per minute and the average expenditure per minute}

Consider a situation in which the price per minute for all calls is $\mathrm{p}$. In this case, it is trivial to verify that the average expenditure per minute and the average revenue per minute are both equal to $\mathrm{p}$.

However, with non linear tariffs, the previous result does not hold. The reason is simple: in the average revenue per minute measurement, all minutes have an equal

\footnotetext{
${ }^{8}$ Spain is divided into 17 Comunidades Autónomas, which are subnational administrative units.
} 
weight -each contributing with its price-, whilst with average expenditure per minute, all individuals, independently on their consumption levels, are treated equally. Therefore, if intensive users benefit from smaller prices, the average revenue per minute will be smaller than the average expenditure per minute.

In what follows we will argue that there are two potential sources that may explain why the price per minute for large users (those that consume more minutes) may be smaller than the price per minute of small users. The first obvious reason is the prominence of volume discounts in the Spanish market place- generally through two part tariffs which specify a fixed minimum monthly fee accompanied with some volume discount (for example, a number of free minutes for some type of calls) and with a price per minute that is charged for the excess minutes over the fixed fee. Usually, a larger fixed fee is associated to a smaller price per minute and/or to a larger volume discount. Therefore, the more an individual makes the most of the volume discount available in his/her tariff the smaller the effective price per minute he or she will pay and the more intensive user an individual is, the more likely it is that he takes up a tariff with a large volume discount.

The second reason is that most operators charge a 15 euro cent fee per call establishment and then a variable price per second, which is a case that we develop in the following subsection using a simple theoretical model.

\subsubsection{Effects of the call connection fee on average revenue per minute and average expenditure per minute: a theoretical approach}

As it has been explained, one of the most common practices of Spanish mobile telephone operators is the call connection fee - this is, a fare which is charged per call independently of the call length or the number of calls. In this section, using some simplifying assumptions (mainly the absence of any other type of non linearity), we will prove that the call connection fee causes average revenue per minute and average expenditure per minute to differ, even in a market with only one tariff.

Consider that, in addition to the per minute charge $\mathrm{p}$, a call connection fee, $\mathrm{c}$, is charged by operators, and, suppose that each individual, $i$, from 1 to $\mathrm{I}$, makes $n_{\mathrm{i}}$ calls and each call, $j$, has a duration equal to $\mathrm{d}_{\mathrm{ij}}$. Finally, we define $\overline{\mathrm{d}}_{\mathrm{i}}$ as the average duration of the calls of individual $i$.

Under these assumptions the average revenue per minute is as follows:

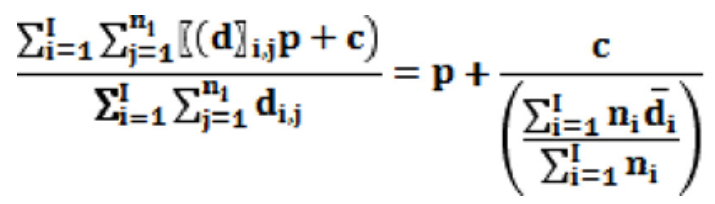


In contrast, the average expenditure per minute equals:

$$
\frac{\sum_{i=1}^{I} \frac{\sum_{j=1}^{n_{1}} \rrbracket\left(d \rrbracket_{i, j} p+c\right)}{\sum_{j=1}^{n_{1}} d_{i, j}}}{I}=p+\frac{c}{\left(\frac{I}{\sum_{i=1}^{I} \rrbracket\left(\frac{1}{\bar{d}_{i}} \rrbracket\right)}\right)}
$$

First, note that the effect of the call connection fee is that the effective price per minute of any call decreases with its length. In consequence, both the average revenue and the average expenditure decrease as calls become longer, as can be seen in expressions [1] (assuming that the $\mathrm{n}_{\mathrm{i}}$ are fixed) and [2]. Indeed, if the average duration of calls is the same for all individuals, average revenue per minute and average expenditure per minute are equal even if the number of calls differ.

Second, the difference between the previous expressions is that in [1] $\mathrm{c}$ is divided by the weighted arithmetic mean of average individual call durations $\left(\overline{\mathrm{d}}_{\mathrm{j}}\right)$, with the weight of each individual being its number of calls, whilst in [2] $\mathrm{c}$ is divided by the unweighted harmonic mean of the average individual call durations $\left(\overline{\mathrm{d}}_{\mathrm{i}}\right)$.

In the case where all individuals make the same number of calls, given that the harmonic mean is always smaller or equal to the arithmetic mean (Hardy et al., 1934), we obtain that the average expenditure per minute exceeds or equals the average revenue per minute. As mentioned, these two only coincide if the average duration of calls is the same for all individuals.

When the number and the duration of calls differ between individuals, the difference between the average revenue and the average expenditure can take any sign: either can be larger than the other. However, for the average expenditure to be smaller than the average revenue, this is, to reverse the relationship obtained when all individuals make the same number of calls, it is necessary that in the weighted arithmetic mean of [1] more weight is assigned to the individuals with shorter calls. This is, there must be some negative correlation between the average call duration and the number of calls of individuals. As mentioned previously, in the average expenditure indicator what we are averaging is the price per minute of each individual across individuals and each individual "price" has a weight of 1/I. In contrast, the information of individuals that make more calls has a stronger impact in the average revenue indicator in comparison with individuals with a few calls. Hence, as expression [1] shows the average revenue would fall if for a given set of individual call durations, the number of calls assigned to individuals with longer calls increased. In effect, a strong positive correlation between the number of calls and the call length of individuals would reduce the average revenue indicator. 


\subsection{Evidence from different data sources}

To illustrate the aforementioned differences we provide evidence for the mobile phone call market that results from the two sources of information at CMT (for Spain). In order to do this we have used, on one hand, the information on the mobile phone bills of the individuals in the bill harvesting data of the second quarter of 2010 and, in the other hand, the aggregated data provided by the operators in the second quarter of 2010 for the post-paid calls. The similarities in average revenue results confirm the validity of the two data sources (13.3 and 15.1 euro cents per minute).

TABLE 1

AVERAGE EXPENDITURES AND REVENUES FOR MOBILE VOICE CALLS

\begin{tabular}{|l|c|c|c|}
\hline \multirow{2}{*}{} & \multicolumn{2}{|c|}{$\begin{array}{c}\text { Panel de hogares } \\
(\mathbf{2 , 4 8 1} \text { individuals })\end{array}$} & $\begin{array}{c}\text { Data provided } \\
\text { by operators }\end{array}$ \\
\cline { 2 - 4 } & $\begin{array}{c}\text { Average } \\
\text { expenditure }\end{array}$ & $\begin{array}{c}\text { Average } \\
\text { revenue }\end{array}$ & $\begin{array}{c}\text { Average } \\
\text { revenue }\end{array}$ \\
\hline Voice calls (euro cents per minute) & 29.1 & 13.3 & 15.1 \\
\hline
\end{tabular}

As table 1 shows the average expenditure per minute is greater than the average revenue per minute. This is in line with what is expected from the arguments in the previous section- as a consequence of volume discounts but also compatible with a situation with call connection fees in the case that there is no correlation between the average length of calls and the number of calls of individuals. Indeed, in the sample the Spearman's rank correlation coefficient is only 0.07 and the Pearson's correlation coefficient is -0.004 .

Another interesting exercise is to see the effect of volumes of minutes consumed on both the average revenue and average expenditure. To do this we report these indicators for each of the quartiles of individuals according to total minutes of consumption ${ }^{9}$.

9 The first, second (median), and third quartile for the minutes consumption distribution were 31.8 , 59.8 and 119.9 minutes, respectively. 
TABLE 2

MINUTES CONSUMED IMPACT ON AVERAGE EXPENDITURES AND REVENUES OF MOBILE VOICE CALLS

\begin{tabular}{|c|c|c|c|}
\hline $\begin{array}{c}\text { Volume of minutes } \\
\text { quartile }\end{array}$ & $\begin{array}{c}\text { Average number of } \\
\text { minutes per month }\end{array}$ & $\begin{array}{c}\text { Average expenditure } \\
\text { (euro cents/minutes) }\end{array}$ & $\begin{array}{c}\text { Average revenue } \\
\text { (euro cents/minute) }\end{array}$ \\
\hline 1st & 18.7 & 59.4 & 40.7 \\
2nd & 44.6 & 26.2 & 25.8 \\
3rd & 84.9 & 19.7 & 19.3 \\
4th & 301.5 & 10.9 & 7.9 \\
\hline Total & 112.4 & 29.1 & 13.3 \\
\hline
\end{tabular}

$\mathrm{N}=2,481$.

The fact that both proxy prices decrease with minutes consumed reinforces the idea that volume discounts are present in the market and are the main cause of the emerging difference between average revenue and average expenditure per minute in the overall sample.

Moreover, the following figure neatly shows that what is driving the difference between the average revenue per minute and the average expenditure per minute is the diversity of minutes consumed by different individuals. The figure indicates the values of the two measurements for each of the $2.5 \%$ percentiles of minutes consumed in the sample. This is, we are calculating the average revenue per minute and the average expenditure per minute grouping individuals with very similar consumption levels. In each group we have roughly 60 individuals, and the average and median increase in minutes from percentile to percentile are of 14.3 minutes and 4.1 minutes respectively. As can be seen, when consumption levels are similar, the two indicators are exactly the same. Notice that in table 2 for each quartile the average revenue was smaller than the average expenditure probably because of the variability of minutes consumed within each quartile. 
FIGURE 1

\section{AVERAGE REVENUE AND AVERAGE EXPENDITURE DEPENDING ON THE $2.5 \%$ PERCENTILES OF VOLUME OF MINUTES CONSUMED}

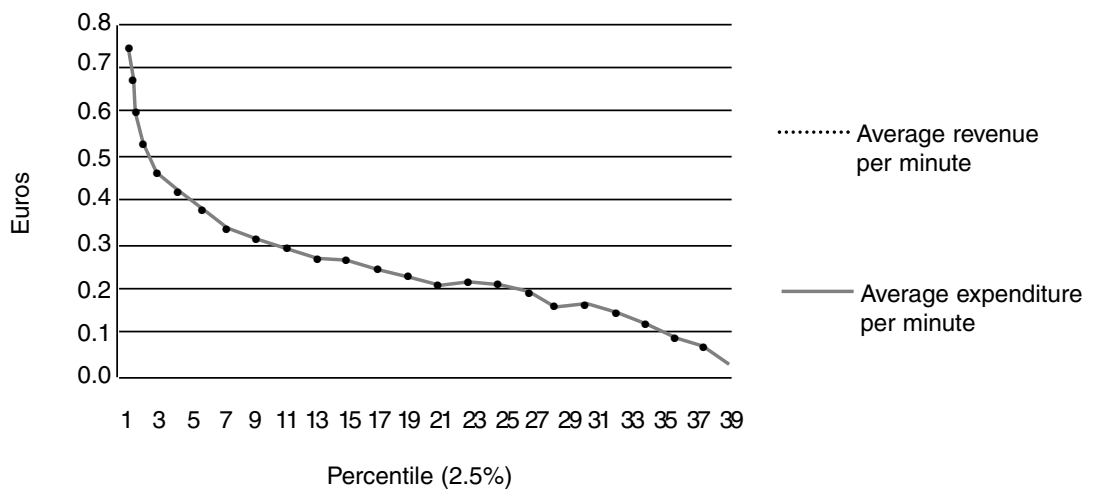

In contrast, if we group individuals as before, but now taking $2.5 \%$ percentiles using the duration of calls ${ }^{10}$, we observe that, for all percentiles, average expenditure per minute is larger than average revenue per minute. Recall that in our call-connection-fee model, when all individuals had the same call durations, the average revenue per minute equated the average expenditure per minute. However, in our real data, even if one compares individuals with very similar call lengths, there is a difference between both measurements. This difference reinforces the idea that, in the presence of volume discounts, the volume of minutes consumed is a major source for differences between both indicators.

FIGURE 2

\section{AVERAGE REVENUE AND AVERAGE EXPENDITURE DEPENDING ON THE 2.5\% PERCENTILES OF DURATION OF CALLS}

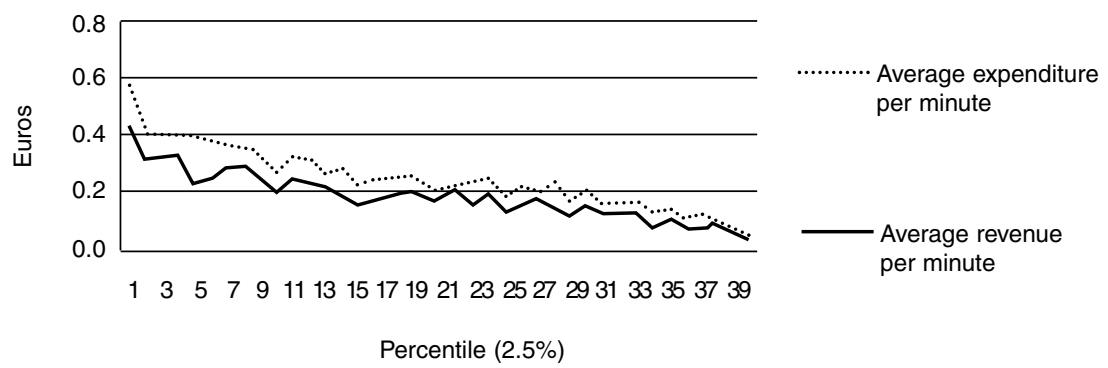

10 The average increases in duration from percentile to percentile are of 10 seconds per call. 


\section{Conclusion}

In this paper, we have shown how two apparently similar ways to report mobile call prices (euros per minute): the average expenditure per minute and the average revenue per minute, may differ in a striking way. In the case of mobile calls, for the second quarter of 2010, average expenditure per minute doubled average revenue per minute. This divergence is due to the widespread use of non-linear mobile call tariffs, very especially, volume discounts, but also call connection fees.

Given all of this, a legitimate question would be: which of the two measures should be used? In our opinion, the answer to such question is that these indicators are complementary in nature and their combination sheds a better light on price levels in markets where price discrimination is present. As we have shown volume discounts, a form of second degree price discrimination, underlie the value of average expenditure per minute, as intensive users self select into tariffs which implicitly result in a smaller price per minute. By reporting data on average expenditure per minute, and even reporting such data according to consumption patterns (volume of minutes consumed) a regulatory authority and the public can get at a richer picture of the degree and effectiveness of price discrimination in the market place.

Moreover, the average expenditure per minute is a better measurement of price levels that the indicators resulting from the tariff basket technology- as those published by the $\mathrm{OECD}^{11}$ that several institutions such as the European Commission regularly use. Unfortunately the latest data available from the OECD is from August 2008 and we can only compare it with our data of the second quarter of 2010. Still, the comparison is revealing. In the case of the high consumption profile (246 minutes per month) the price per minute implied from OECD's figures for Spain is 20 euro cents, whilst the consumers in the relevant $2.5 \%$ percentile $^{12}$ spend 9 euro cents per minute. For the medium consumption profile (114 minutes per month), the OECD figure is 21 cents per minute, and the $2.5 \%$ percentile figure is 15 cents per minute, and finally in the case of the low consumption profile (44 minutes per month), the two figures are similar: 23 euro cents per minute (OECD) and 26 euro cents per minute $(2.5 \%$ percentile). However, we must notice that the OECD existing mobile basket methodology does not include volume discount tariffs. The inclusion of these tariffs could make the figures more similar.

Finally, one must bear in mind that to derive the average expenditure per minute as we do, it is mandatory to have access to household level data and unfortunately, this kind of data is still scarce.

\footnotetext{
11 http://www.oecd.org/document/5/0,3746,en_2649_34225_43877509_1_1_1_1,00.html

12 The percentile that includes 246.
} 


\section{References}

[1] ERG report, "Methodology on the proposal for comparison of broadband retail prices, based on the analysis of strengths and weaknesses of existing approaches. Available at: http://www.erg.eu.int/doc/publications/erg_08_44_final_bb_retail_prices_methodology_ 081017.pdf

[2] HARDY, G. H.; LITTLEWOOD, J. E. and POLYA, G. (1934): «Inequalities», Cambridge University Press. 